\title{
Effective Offshore Piling Noise Mitigation in Deep Waters
}

\author{
Karl-Heinz Elmer \\ OffNoise-Solutions GmbH, 31535 Neustadt, Marktstrasse 5, Germany
}

\begin{abstract}
Underwater noise is a severe annoyance and danger to marine life. The innovative HSD (hydro sound damper) leads to an effective general method to reduce underwater noise. HSD was developed and patented between 2007 and 2010 by the author to reduce general marine noise and especially offshore piling noise. The theory and the acoustical background of the new noise mitigation method will be presented. HSD systems use nets with gas filled elastic balloons and special PE-foam elements with high dissipative effects to reduce continuous and impact noise. The resonance frequency of the HSD-elements, the optimum damping rate for impact noise, the distribution and the effective frequency range can be fully controlled. Offshore tests and serial applications in offshore wind farms in Germany and Great Britain demonstrate this new effective way to reduce the very high offshore piling noise. HSD systems are very small systems and easy to handle. They are independent of external air supply, not influenced by tidal currents, not expensive and easy adaptable to different applications. Underwater noise reductions by HSD systems and bubble curtains are measured by an independent acoustics institute when using the biggest hammers in the world. Achieved results between $14 \mathrm{~dB}$ (decibels) (SEL—sound exposure level) and more than $27 \mathrm{~dB}$ (SEL) are presented and discussed.
\end{abstract}

Key words: Wind turbines and windfarms, transient or impulsive noise, scattering, resonant absorbers, construction noise, underwater noise mitigation.

\section{Introduction}

Hydraulic impact hammers induce considerable underwater sound emissions. The construction noise of offshore wind turbines is potentially harmful to marine life. Different zones of underwater noise immissions can be defined in the surrounding of an acoustic noise source of about $30 \mathrm{~km}$ and more [1].

Due to today larger piles requiring higher driving energies, even higher underwater noise levels are expected in future projects, accompanied by an increasing number of wind turbines. Effective noise reducing methods are in great demand, getting sound levels below recommended acoustic emission thresholds that are no longer harmful or disturbing to marine life [2].

\subsection{Underwater Piling Noise Measurement}

Underwater piling noise is usually described by two sound levels [3]. The first level is the peak SPL

Corresponding author: Karl-Heinz Elmer, Dr.-Ing., research fields: transient dynamics, wave propagation, pile dynamics and noise mitigation. (sound pressure level) in $\mathrm{dB}$ (decibels) of the maximum instantaneous pos. or neg. sound pressure $\left|p_{\text {peak }}\right|$ of the measured impact noise that is referred to the underwater sound pressure of $p_{0}=1 \mu \mathrm{Pa}$ :

$$
\text { peak } S P L=20 \log \left(\frac{\left|p_{\text {peak }}\right|}{p_{0}}\right)
$$

The second level for describing pile driving underwater noise is the SEL (sound exposure level) in decibels (e.g. $\mathrm{dB}$ re: $1 \mu \mathrm{Pa}^{2}$ s), which is an equivalent energy level of the noise of a single pile driving impulse, based on $T_{0}=1 \mathrm{~s}$ :

$$
S E L=10 \log \left(\frac{1}{T_{0}} \int_{T 1}^{T 2} \frac{p(t)^{2}}{p_{0}^{2}} d t\right)
$$

The SEL is the level of a continuous sound with $1 \mathrm{~s}$ duration and the same sound energy as the pile driving impulse.

Measurements of underwater piling noise show peak levels of more than $210 \mathrm{~dB}$ (SPL) and sound exposure levels of more than $180 \mathrm{~dB}$ (SEL) at $750 \mathrm{~m}$ distance from pile driving sites, depending on ram energy and pile size. 


\subsection{Standard Levels of Underwater Piling Noise}

The BSH (German Federal Maritime and Hydrographic Agency) has set the standard sound exposure level of $160 \mathrm{~dB}$ (SEL) and the peak level of $190 \mathrm{~dB}$ (SPL) at $750 \mathrm{~m}$ distance from offshore pile driving sites as part of the building permission of offshore wind farms. Effective noise reducing methods are necessary to achieve these standard levels.

Offshore applications of air bubble curtains are expensive at big water depth and currents. The main problems are the compressed air supply, the control of the bubble size, the installation of air pipes on the ground and the influence of water currents together with slow ascent rates of the bubbles.

\section{Theory of HSD (Hydro Sound Damper)}

To overcome these problems, a new underwater noise reducing method is developed, using gas filled enveloped bodies and PE-foam elements as hydro sound dampers, instead of free air bubbles.

In contrast to conventional air bubbles, HSDs of both kinds, gas filled bladders and PE-foam elements allow to use three different physical effects for underwater noise attenuation:

- Reflections of sound waves at impedance steps from water, filled with hydro sound dampers;

- Resonance effects with high scattering, multiple reflections and absorption of sound waves;

- Dissipation of acoustic waves according to material damping effects of HSD elements.
The important resonance effects with high scattering, multiple reflections and effective absorption of sound waves in water are shown in Fig. 1. There is to be seen a very strong interaction of a vibrating HSD-element at the surrounding water surface. This interaction also takes place around HSD elements under water, but it is not visible there.

The size of the bodies, the effective frequency range, the selected material and the damping rate, the number and distribution of the HSD and the influence from hydrostatic pressure can be fully controlled, if the envelope bodies are fixed to a pile surrounding fishing net after Fig. 2 or to stiff frames.

HSD is used in the whole frequency range of pile driving noise. Special types of materials and elements are developed to optimize absorption and damping effects. Finally, HSD elements do not need compressed air supply.

\section{Noise Mitigation Test of HSD}

For a first offshore test during pile driving in the German Baltic Sea a prototype of the HSD system was a self-swimming construction with winches to lower three different types of HSD nets to seabed [4]. All elements of the same size were tuned to the resonance frequency of $120 \mathrm{~Hz}$ to get reduced noise transmissions in a very effective way within the most important lower frequency range around $120 \mathrm{~Hz}$.

The radiated underwater sound pressure was measured at $4 \mathrm{~m}$ above the ground at a distance of $6 \mathrm{~m}$ from the pile to get most of the directly radiated noise and to avoid influences from the water surface and

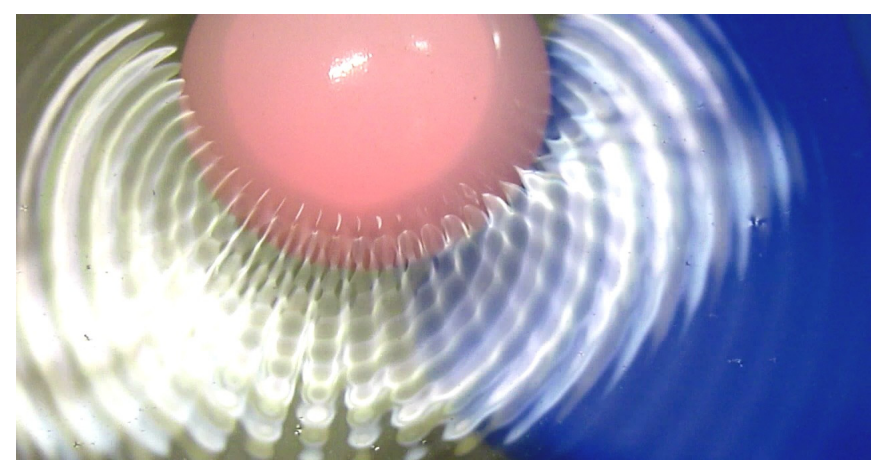

Fig. 1 Scattering, radiation and interaction [2]. 


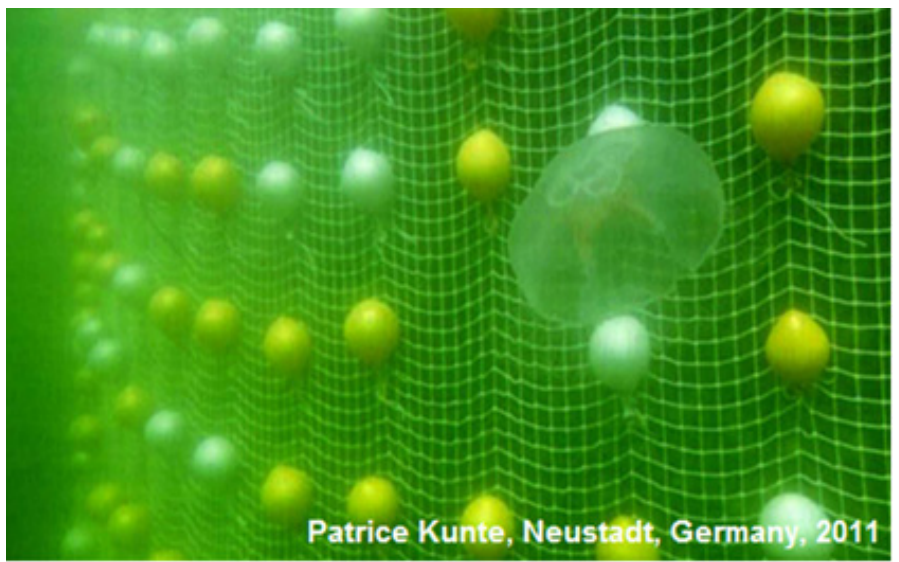

Fig. 2 HSD net and elements under water [3].

from the sea ground. Fig. 3 shows the 1/3 octave SEL spectrum of the original piling noise and the reduced sound exposure level after applying HSD noise mitigation of both, gas filled balloons and PE-foam element.

The measured underwater noise mitigation of about $23 \mathrm{~dB}$ (SEL) means that $99.5 \%$ of the whole sound energy is damped out by the HSD net after Fig. 2 .

This result is very interesting, as the used HSD-net is only covered by HSD-elements at about $5-10 \%$ of the net surface. Thus, the measured results show, that it is possible to realize a screen of more than $90 \%$ permeability to current water and to water waves, but at the same time building an impermeable barrier to underwater noise of up to $99.5 \%$ of the noise energy.

This result is very remarkable as it is well known from acoustics and sound isolations, that already a small opening of $5-10 \%$ of the isolation like a tilted window breaks down the whole effect of sound isolation. The opening of the HSD-net is more than $90 \%$ of the net surface where water can flow through it.

\section{Offshore Applications of HSD Systems}

During pile driving of big monopiles into the sea ground sound waves are not only radiated into the surrounding water. There are also radiations of vibrational waves from the pile surface deep into the layered ground. Parts of these waves can reach the surface of the sea ground and induce additional sound waves in the water, far away from the piling site. To reduce this indirect underwater noise, additional bubble curtains are used at a distance of $100 \mathrm{~m}$ around the piling site.

\subsection{HSD-System}

The whole HSD system with the HSD net around a pile, the HSD-box on the sea ground as the counterweight to the buoyancy forces of the net and the steel wires with the winch frame are visualized in Fig. 4.

\subsection{HSD Net and HSD Box}

The HSD net is fixed to the ground of the HSD box and folded in this basket for transport. Before piling the HSD box is set around the pile while hanging below the PGF (pile guiding frame) of the installation vessel after Fig. 5.

For piling the HSD box with the net inside is lowered to the sea ground while the net is fully extended around the pile from the sea ground up to the water surface after Fig. 6.

In Fig. 7 an installation vessel with piling device and HSD system of an offshore project is shown.

Comparable to the situation in Fig. 6 the net box is laying on the sea ground, the net is expanded around the pile and swimming up to the surface of the water. The HSD system is hanging below the winch frame (blue device) that is situated below the pile gripper frame PGF (green device) of the installation vessel for 


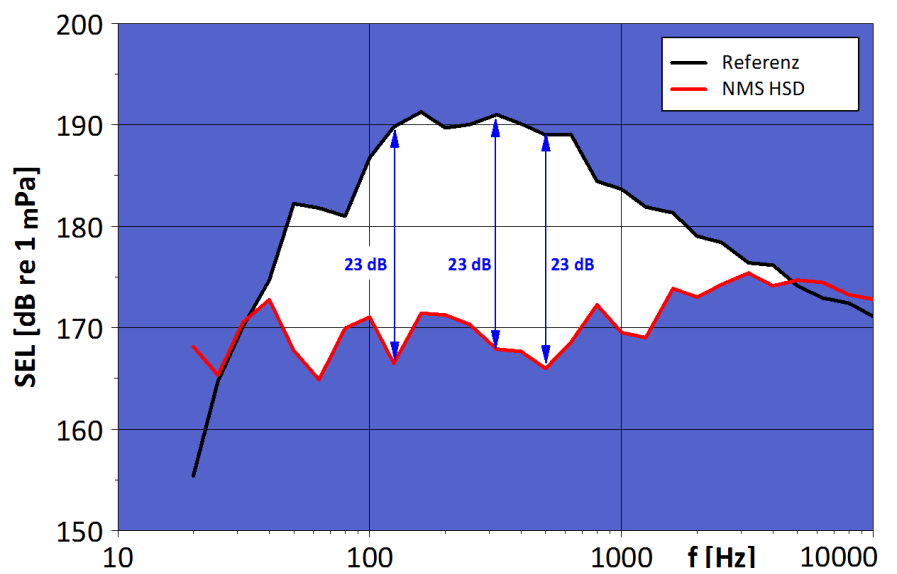

Fig. 3 Third octave SEL spectra of underwater piling noise w/o HSD noise mitigation [4].

General concept of the HSD-System for a monopile

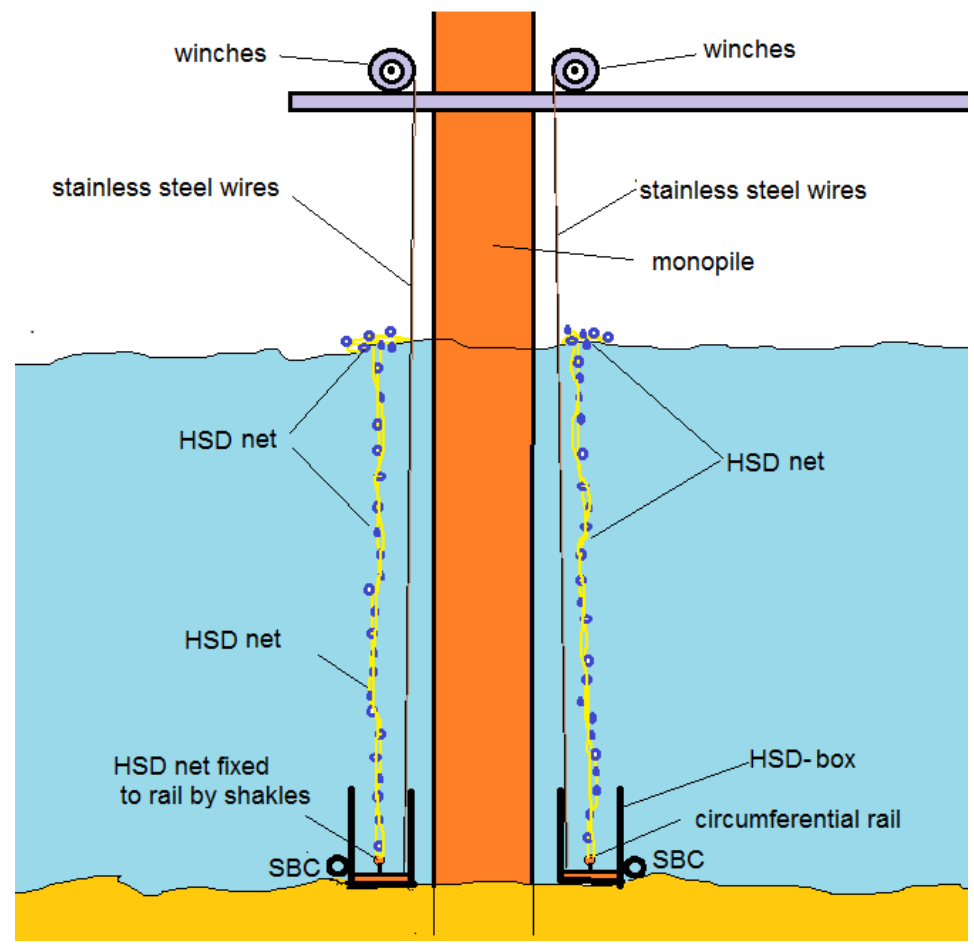

Fig. 4 HSD-system with HSD-net around a pile and with HSD-box on the ground [5].

precise positioning of the monopile. The hydraulic hammer (yellow) on top of the pile is the Menck MHU 3500S with up to $3500 \mathrm{~kJ}$.

\section{Achieved Noise Mitigation of HSD Systems}

The HSD system was located on a separate winch frame (blue device) below the PGF in Fig. 7. With this solution the net box was controlled in parallel to other works of the main hook which caused not any time delay and deck space for the HSD noise mitigation. The resulted noise mitigation of the Offshore Windfarm "Sandbank" (2015) in the German North Sea using a HSD-System in combination with a double big bubble curtain was between 19-27 dB (SEL) after Table 1. 


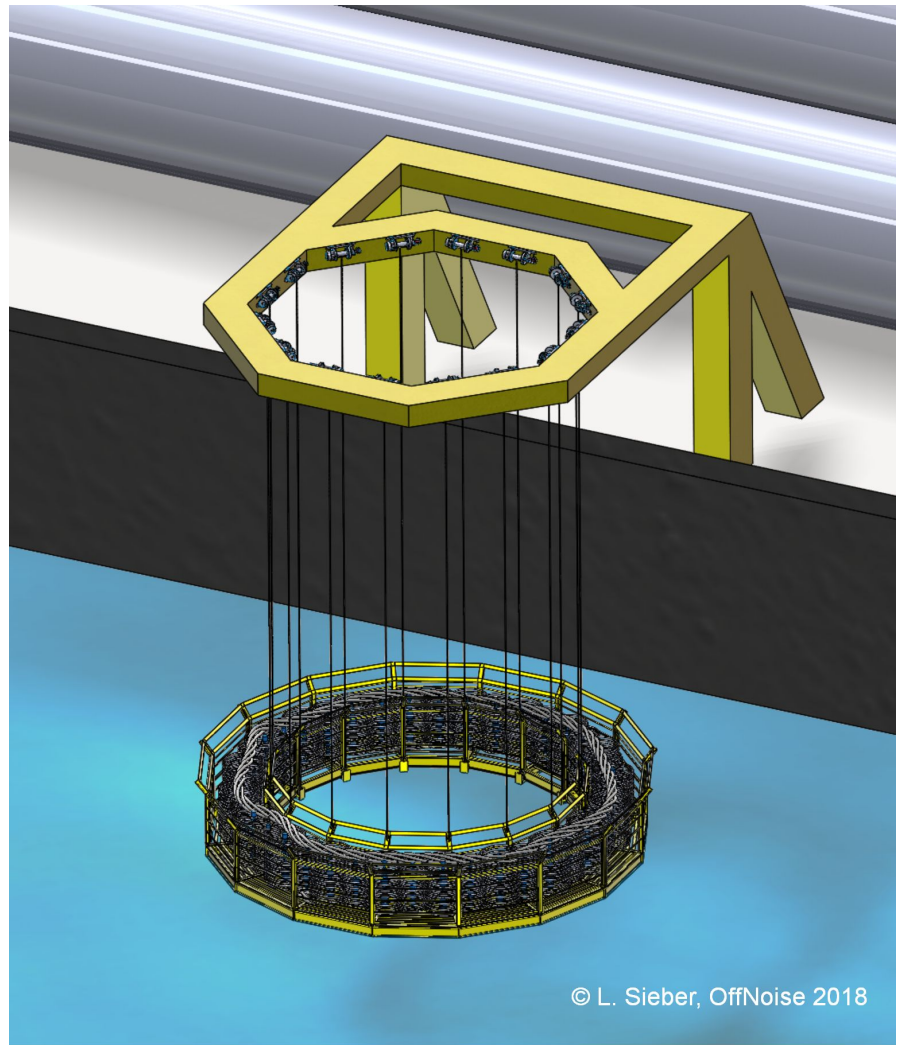

Fig. 5 HSD-Net folded in a basket before piling.

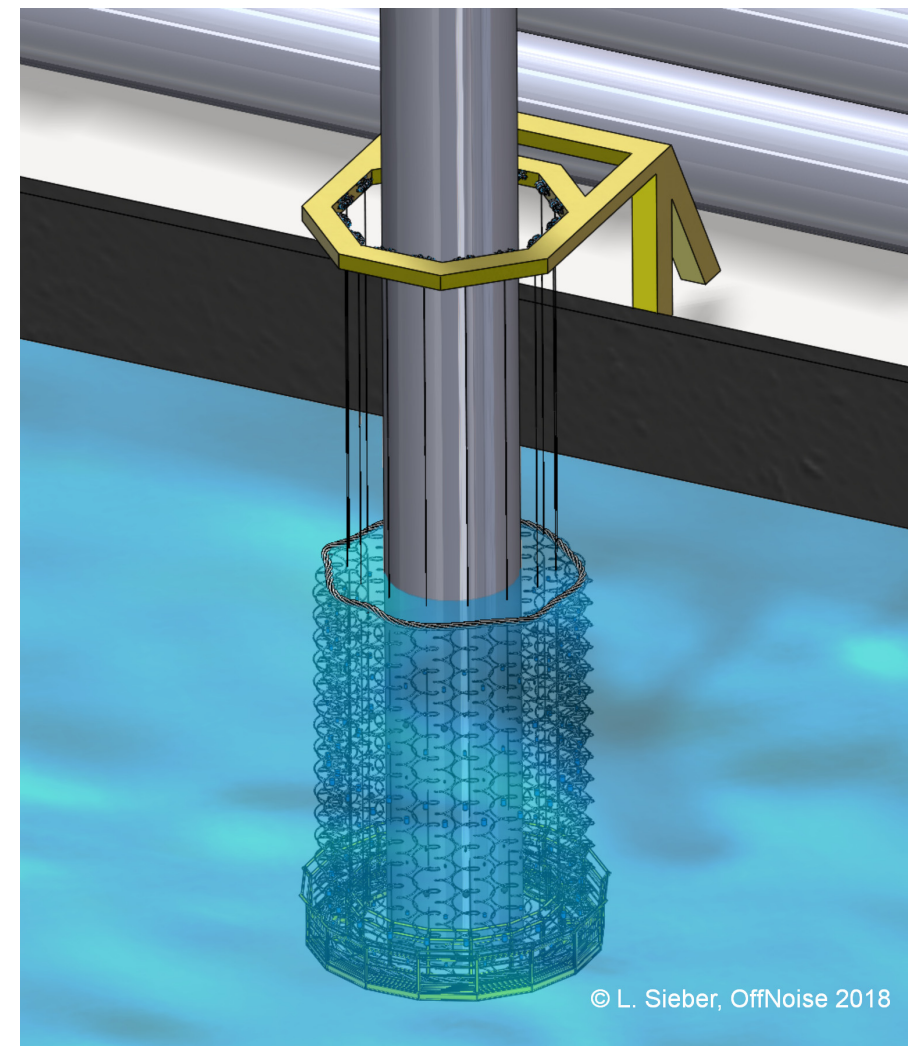

Fig. 6 Box on the ground; Net is fully expanded. 


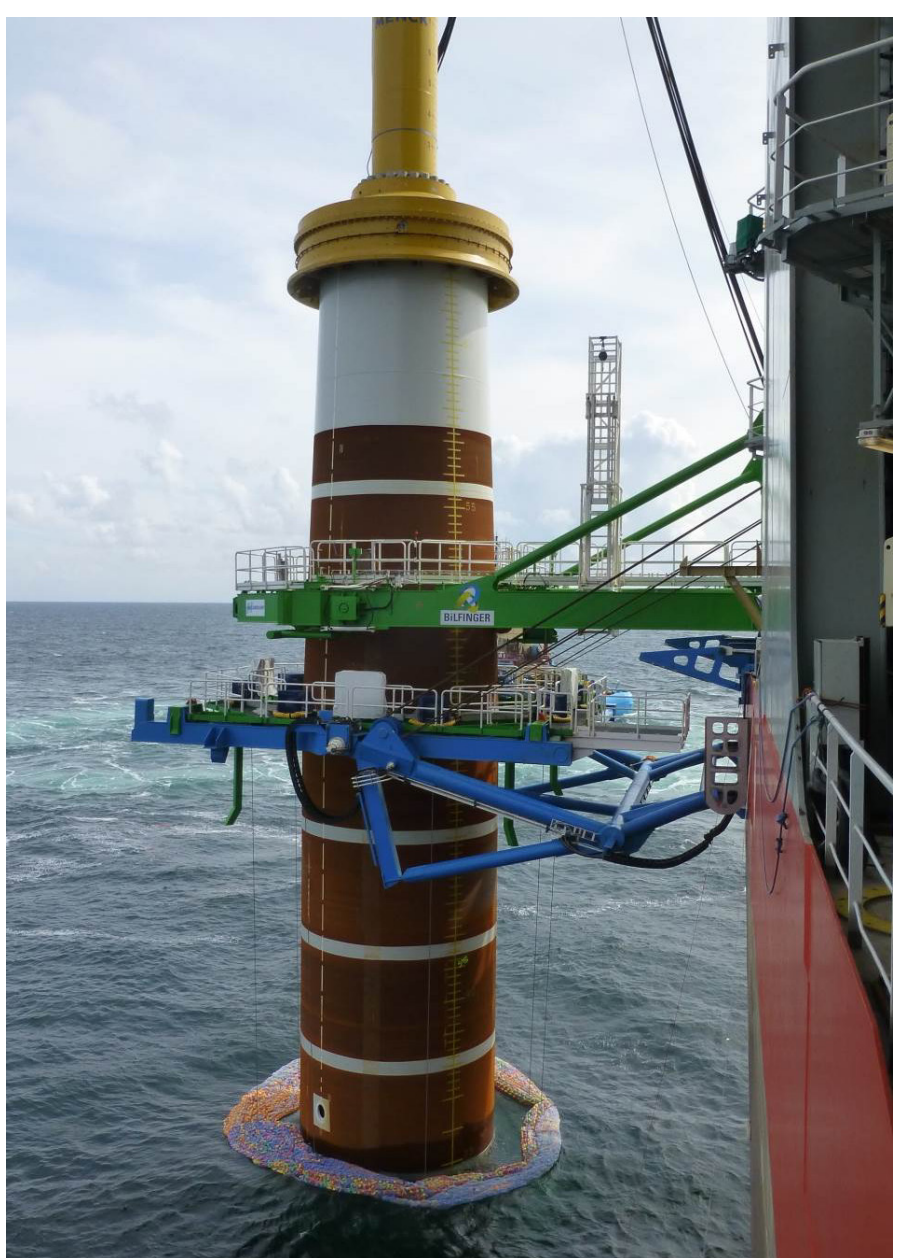

Fig. 7 Expanded HSD net for $\mathbf{4 0} \mathbf{m}$ water depth.

Table 1 Developing process of HSD systems.

\begin{tabular}{llllll}
\hline Offshore Wind Farm & Amrumbank & Sandbank & Veja Mate & Wikinger & Arkona \\
\hline Year & 2012 & $2014-2015$ & 2016 & 2016 & 2017 \\
Foundation & Monopile & Monopile & Monopile & Jacket, prep. & Monopole \\
Pile diameter & $6.0 \mathrm{~m}$ & $6.8 \mathrm{~m}$ & $7.8 \mathrm{~m}$ & $2.7 \mathrm{~m}$ & $7.8 \mathrm{~m}$ \\
Water depth & $25 \mathrm{~m}$ & $34 \mathrm{~m}$ & $40 \mathrm{~m}$ & $40 \mathrm{~m}$ & $40 \mathrm{~m}$ \\
Hammer type & MHU 1900S & MHU 3500S & IHC S-4000 & MHU 1200S & IHC S-4000 \\
HSD implementation & Connected to hammer & Separate frame & Separate frame & Separate frame & Openable net box \\
Noise reduction, dB (SEL) & $14 \leq 16 \leq 22$ & $19 \leq 22 \leq 27$ & $18 \leq 20 \leq 24$ & Not published & Not yet published \\
Using HSD + DBBC & & & &
\end{tabular}

\section{Results and Discussions}

The innovative HSD is a cost-effective method of attenuating underwater piling noise in offshore marine piling projects. HSD is also applicable as an effective general method for reducing any kind of underwater noise and piling noise in ports and harbors. HSD achieves high reductions even in the presence of strong tidal currents or rivers. In combination of HSD systems with DBBC (double big bubble curtains) noise mitigations are measured between 19 and up to $27 \mathrm{~dB}$ (SEL). HSD systems are small and easy to handle and are patented in several countries [6].

\section{Conclusions}

The use of HSD will significantly reduce the observation area required during piling operations and 
provide improved protection of the marine environment from potential adverse impacts upon marine life from impulsive and cumulative underwater piling noise exposure [1].

HSD elements are optimal tuned to special low frequencies of the noise spectrum of today's big hammers, of future piles of more than $10 \mathrm{~m}$ diameter and of water depths of up to $40-60 \mathrm{~m}$.

\section{References}

[1] Elmer, K.-H., Betke, K., and Neumann, T. 2007. Standard Procedures for the Determination and Assessm. of Noise Impact on Sea Life by Offshore Wind Farms, in German. Research report, BMU 0329947.

[2] Elmer, K.-H. 2010. "New Hydro Sound Dampers to
Reduce Underwater Piling Noise Emissions." Paper presented on the DEWEK 2010 Conference, Bremen, Germany.

[3] Elmer, K.-H. 2014. "Effective Reduction of Offshore Piling Noise." In Proceed. of the 2nd Underwater Acoustics Conference and Exhibit. (UA 2014), 295-300.

[4] Elmer, K.-H., Bruns, B., and Kuhn, C. 2016. "Offshore Piling Noise Attenuation: Theory and New Applications on Monopiles and Jacket Foundations." In Proceed. of Inter-noise 2016 Conference, 7169-79.

[5] Elmer, K.-H. 2017. "Effective Noise Mitigation for Today's Very Big Piling Systems in Deep Waters.” Paper presented on the DEWEK 2017 Conference, Bremen, Germany.

[6] Elmer, K.-H. 2014. Device for Damping and Scattering Hydrosound in a Liquid. US Patent 8,636,101 B2, filed April 1, 2009, and issued Jan. 28, 2014. 